\title{
モヤモヤ病成人例に対する脳血管の間接的吻合術の効果
}

\author{
永井 成樹, 宮坂 佳男, 吉田 孝友, 小林 郁夫 \\ 倉田彰, 遠藤 昌孝, 森井 誠二, 矢田 賢三
}

\section{Effect of Indirect Cerebrovascular Anastomosis in Adult Moyamoya Patients}

Shigeki Nagai, M.D., Yoshio Miyasaka, M.D., Takatomo Yoshida, M.D., Ikuo Kobayashi, M.D., Akira KuRata, M.D., Masataka Endo, M.D., Seiji Moril, M.D., and Kenzoh YADA, M.D.

Department of Neurosurgery, Kitasato University School of Medicine, Sagamihara, Japan

Summary : This is a report of 6 adult patients of moyamoya disease. We discuss the effects of the indirect cerebrovascular anastomosis.

Two of these patients, presented with ischemia and the other 4 presented with hemorrhage.

The postoperative follow-up ranged from 18 months to 105 months. Two hemorrhagic patients showed rebleeding. In patients who presented with ischemia, adequate neovascularization and prevention of recurrence were obtained with indirect cerebrovascular anastomosis. However, in patients who presented with hemorrhage, this indirect operative method gave unsatisfactory results.
Key words :

- moyamoya disease

- clinical course

- neovascularization

- encephalo-myosynangiosis (EMS)

- indirect cerebrovascular anastomosis

$$
\text { はじめに }
$$

モヤモヤ病の症状は成人例，小児例で異なり，成人例で は頭蓋内出血, 小児例では脳虚血症状の多いことが知られ ている ${ }^{11) 13) 17)}$ 。一方，本疾患に対する外科的治療の効果 も成人例，小児例で異なるようである．すなわち，小监例 では直接的脳血管吻合術, 間接的脳血管吻合術のいずれも が脳虚血症状の再発防止に有効であるとする報告が一般的 である 2)316)7). しかし成人例に対する外科的治療の有効性 については，小览例ほど見解の一致を見ていない5)8)9910) 12) 15) 16)

我々は本疾患成人例に対して, first choice として間接 的脳血管吻合術を施行してきたが，その治療効果について 検討したので報告する.
対象および方法

1973 年から 1991 年までに診断が確定し，手術を行った 本疾患成人例 6 例を対象とした (Table 1). 年齢は 19 45 歳 (平均 32.2 歳), 男性が 2 例, 女性が 4 例, 出血例が 4 例, 虚血例が 2 例 (半身の一過性不随意運動が 1 例, 半身 の一過性知覚障害が 1 例)であった.

外科的手術は術前の脳血管写, 脳血流測定などを参考と して, 基本的には神経症状と関連性のある側, ないし部位 に行った。

最も多く施行された外科的手術は encephalo-myosynangiosis (EMS) であり, 虚血例の 2 例 2 側, 出血例の 3 例 5 側に行われた。この手術は以下のようになされた。 まず皮切は浅側頭動脈を傷つけないように, 同動脈のやや 
後方に，後方凸の弧状に行った. 次いで，皮切部を前後に 開き, 側頭筋を後縁から上縁に沿って切開し, 側頭筋を頭 蓋骨から剝離した．開頭はできるだけ広範囲の側頭筋が脳 表に接することができるように行った. 硬膜切開は硬膜動 脈からの側副血行を障害しないことと, できるだけ筋肉と 脳表の接地面が大きくなることを目標にして, 個々の症例 で異なった方法が採られた，次いで，浅側頭動脈からの血 行を保ったままの側頭筋を脳表に移行した．術後の髄液漏 に注意して，側頭筋，筋膜と硬膜の縫合を密にした.

開頭，すなわち， EMS の大きさは約 $10 \sim 27 \mathrm{~cm}^{2}$ (平均 $\left.17.4 \mathrm{~cm}^{2}\right)$ であり, 虚血例では平均 $13.5 \mathrm{~cm}^{2}$, 出血例では 平均 $19 \mathrm{~cm}^{2}$ であった。

また, 出血例の 1 例 2 側では EMS は施行せず, 術前の 脳血管写で, 側副血行路の少ない部位に硬膜切開を加えた burr hole ${ }^{1)}$ を行った.

follow-up は全例になされ，その期間は 18〜105 カ月 (平 均 65 力)であり,この期間における症状の再発の有無に ついて検討した。 また, 術後の外頸動脈写をもとに, neovascularization の程度を便宜的に軽度 $(+)$, 中等度 $(++)$, 高度 $(+++)$ の 3 段階に分類した (Fig. 1). 術後の脳血管 写を施行した 5 例について, neovascularizationの程度と 症状の再発との関係について検討した (Table 2). なお脳 血管写は術後 9〜50 カ月 (平均 33 力月) に施行された.

\section{結 果}

\section{1. neovascularization の程度}

術後の脳血管写が施行された 5 例の術前, 術後の脳血管 写を Fig. 2〜6に示した. 虚血例 (Case 1,2)ではFig. 2, 3
Table 1 Initial symptoms and operative method of six patients

\begin{tabular}{|c|c|c|c|c|}
\hline Cases & $\begin{array}{l}\text { Age } \\
(\mathrm{Y})\end{array}$ & Sex & $\begin{array}{c}\text { Initial } \\
\text { symptoms }\end{array}$ & $\begin{array}{c}\text { Operative } \\
\text { method }\end{array}$ \\
\hline 1 & 29 & $\mathrm{~F}$ & involuntary movement & Lt. EMS \\
\hline 2 & 35 & $\mathrm{~F}$ & dysesthesia & Lt. EMS \\
\hline 3 & 19 & M & hemorrhage & $\begin{array}{l}\text { Rt. EMS } \\
\text { Lt. EMS }\end{array}$ \\
\hline 4 & 32 & $\mathrm{~F}$ & hemorrhage & $\begin{array}{l}\text { Rt. } \mathrm{BH} \\
\text { Lt. } \mathrm{BH}\end{array}$ \\
\hline 5 & 33 & M & hemorrhage & $\begin{array}{l}\text { Rt. EMS } \\
\text { Lt. EMS }\end{array}$ \\
\hline 6 & 45 & $\mathrm{~F}$ & hemorrhage & Lt. EMS \\
\hline
\end{tabular}

EMS = encephalo-myo-synangiosis

$\mathrm{BH}=$ burr hole with dural incision

に示すように, 術後の脳血管写では EMSを通じて $(+++)$ のeovascularization が認められた。 また, 出血 例 (Case 4, 5,6) では, Case 4 (Fig. 4) で burr hole を介し た $(++)$ の neovascularization が見られ，Case 5 (Fig. 5) では, EMSを介した $(++) の$ neovascularization が認め られた. Case 6 (Fig. 6) では, ごく軽度の $(+)$ neovascularization しか見られなかった.

\section{2. 虚血例の治療成績（Table 2)}

虚血例の 2 例は経過観察期間中に虚血症状の再発はなく また出血も見られなかった。これら 2 例では neovascularization が豊富であり (Fig. 2,3), 良好な治療成績と相関し た。

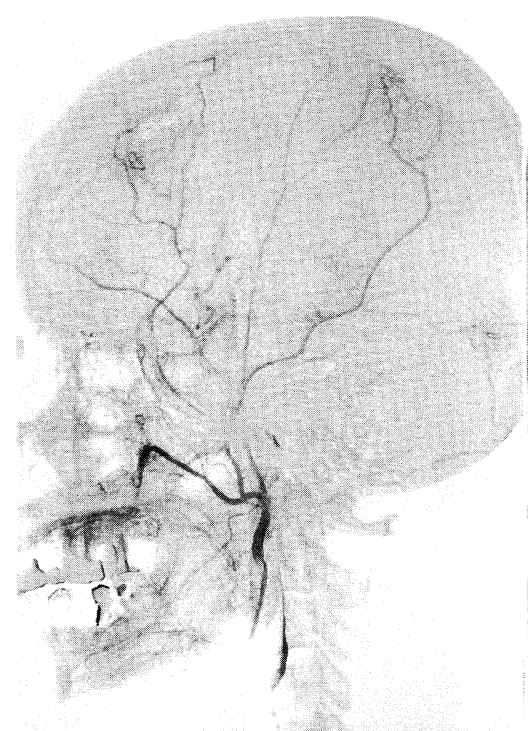

Fig. 1 Left carotid angiograms after encephalo-myo-synangiosis (EMS) operation show mild (+) (A), moderate $(++)(\mathbf{B})$, and marked $(+++)(\mathbf{C})$ neovascularization.

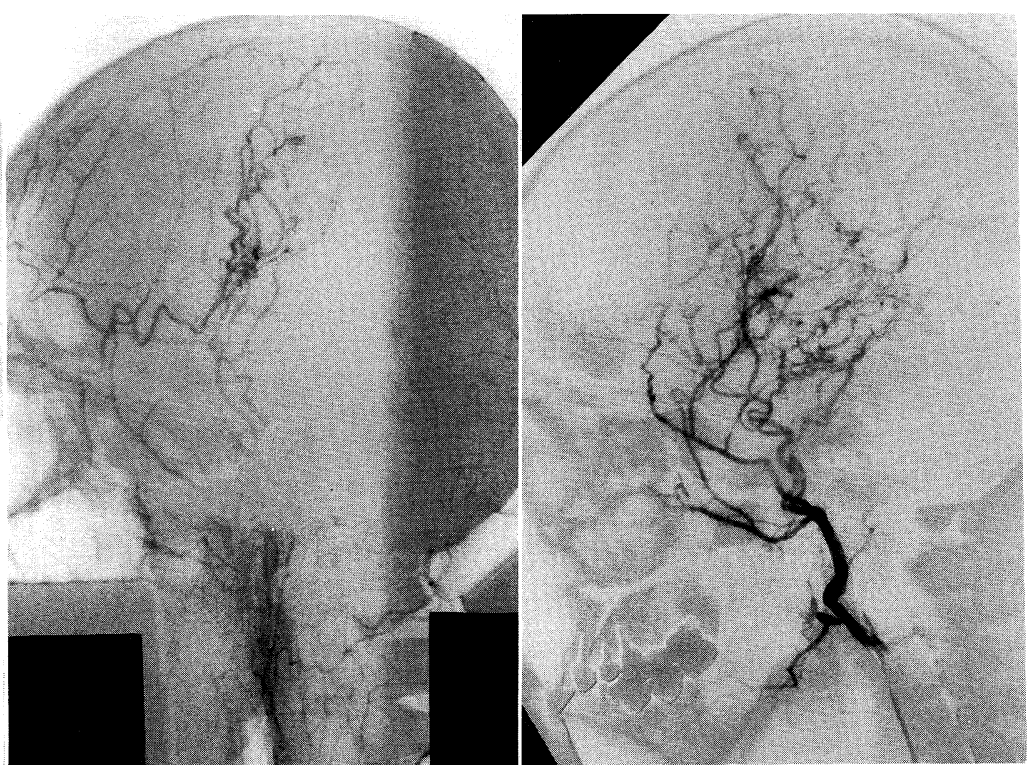


Table 2 The relationship between neovascularization and clinical course

\begin{tabular}{ccccc}
\hline Cases & Clinical course & $\begin{array}{c}\text { Follow-up } \\
\text { period } \\
\text { (month) }\end{array}$ & $\begin{array}{c}\text { Angiographic } \\
\text { neovascularization }\end{array}$ & $\begin{array}{c}\text { Time of postop. } \\
\text { angiography } \\
\text { (month) }\end{array}$ \\
\hline 1 & no CVA & 93 & $(+++) \mathrm{lt}$ & 36 \\
2 & no CVA & 34 & $(+++) \mathrm{lt}$ & 28 \\
\hdashline 3 & no CVA & 66 & not determined & not examined \\
4 & no CVA & 18 & $\begin{array}{c}(++) \mathrm{rt} \\
(++) \mathrm{lt}\end{array}$ & 9 \\
5 & rebleed & 105 & not determined* \\
$(++) \mathrm{lt}$ & 42 \\
6 & rebleed & 72 & $(+) \mathrm{lt}$ & 50 \\
\hline
\end{tabular}

$\mathrm{CVA}=$ Cerebrovascular accident

* = Selective external carotid angiogram can not be undertaken.

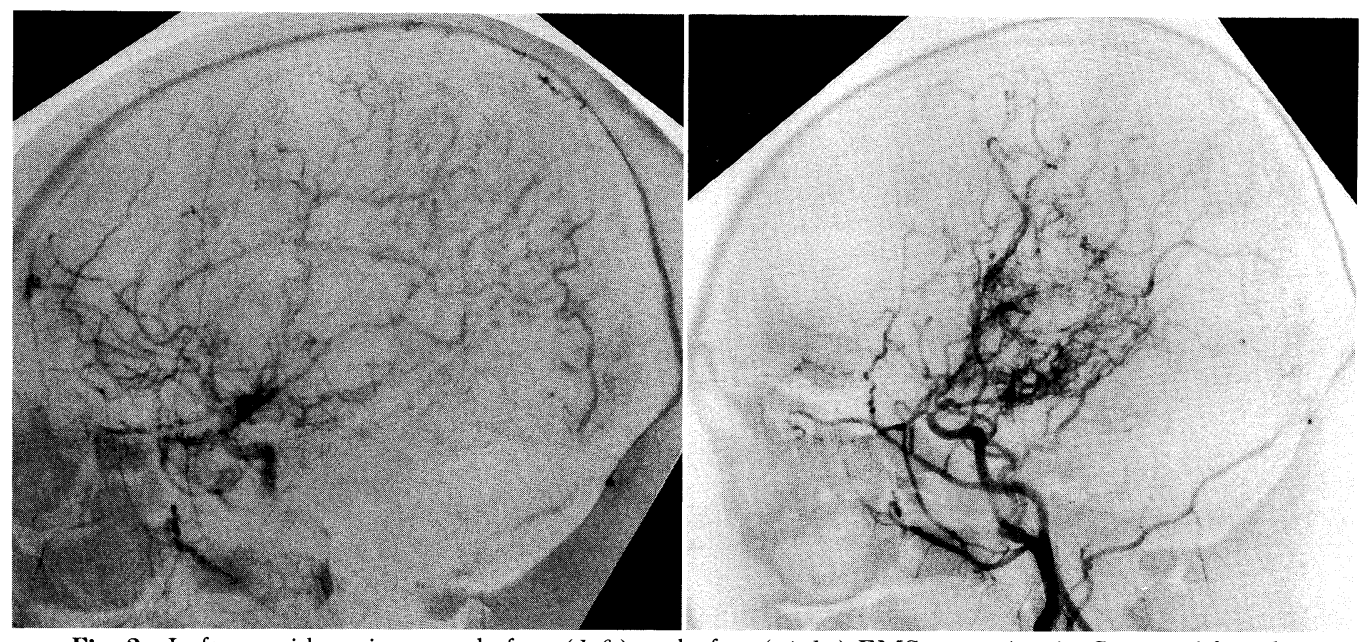

Fig. 2 Left carotid angiograms before (left) and after (right) EMS operation in Case 1. After the operation marked neovascularization $(+++)$ was observed in the temporo-fronto-parietal, previously avascular area.
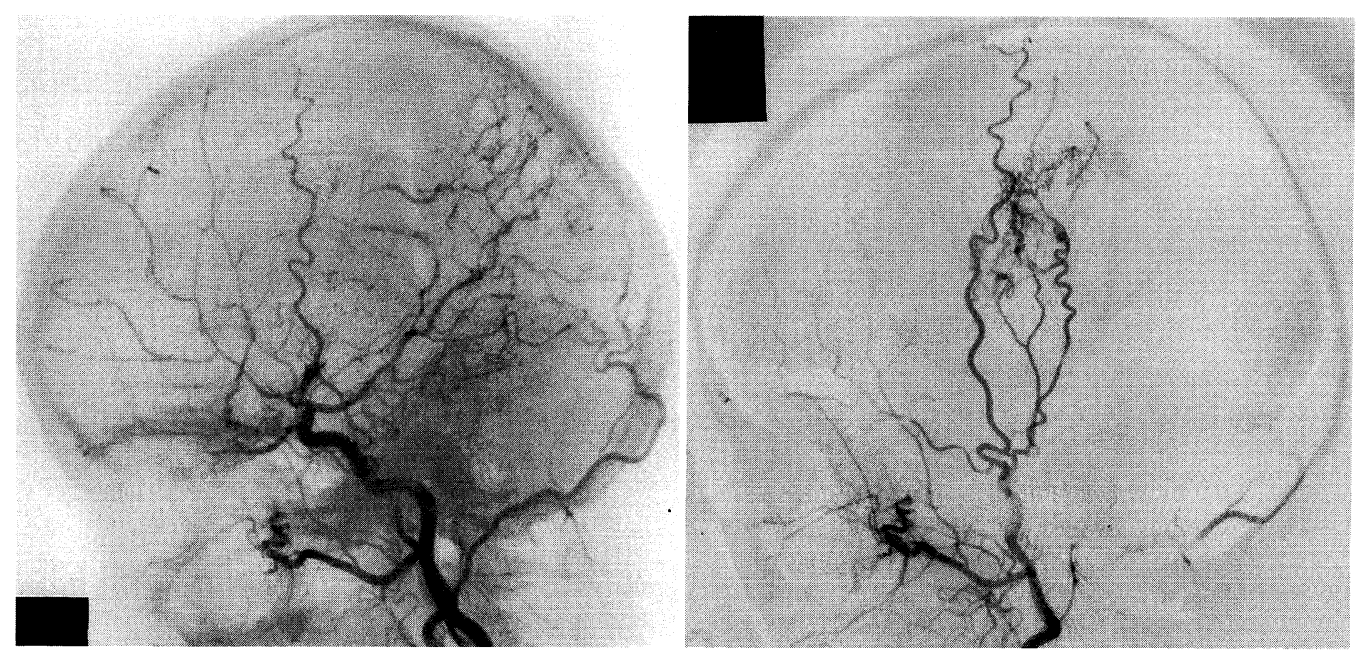

Fig. 3 Carotid angiograms before (left) and after (right) EMS operation in Case 2. After the operation marked neovascularization $(+++)$ was observed in the front-parietal, previously avascular area. 


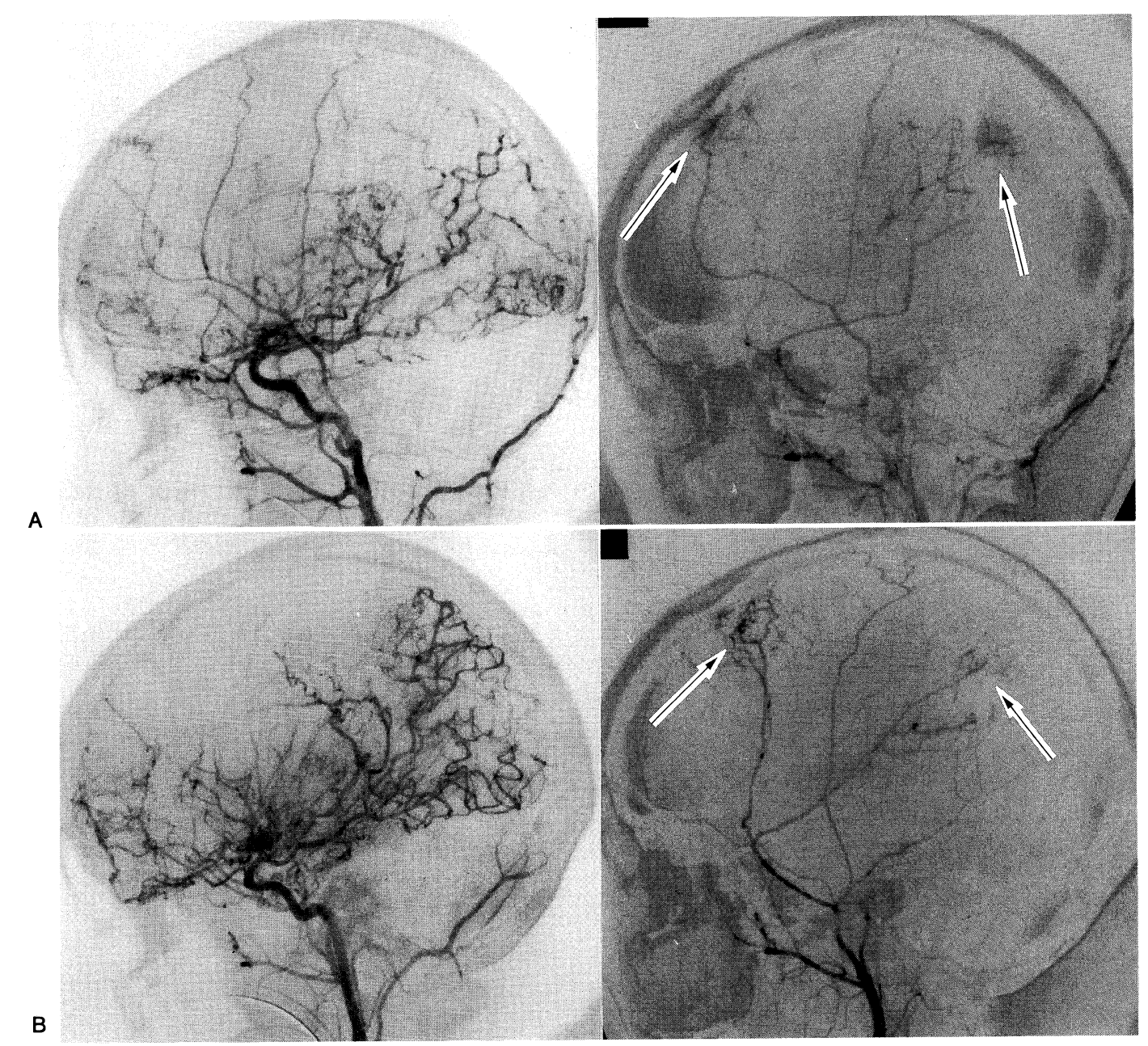

Fig. 4 A: Right carotid angiogram before (left) and after (right) burr hole (BH) operation in Case 4. After operation, moderate neovascularization $(++)$ was observed in the frontal and parietal, previously avascular area (arrows). B: Left carotid angiograms before (left) and after (right) $\mathrm{BH}$ operation in Case 4. After the operation, moderate neovascularization $(++)$ was observed in the frontal and parietal, previously avascular area (arrows).

\section{3. 出血例の治療成績（Table 2)}

出血例 4 例中 2 例では，再出血およびその他の脳血管障 害をきたしていない. しかし, 他の 2 例では, 各々, 術後 70 力月後 (Case 5), 12 力月および 26 カ月 (Case 6, Fig. 7)に再出血が見られた。

これら，出血例では虚血例ほど豊富な neovascularization は見られなかったものの $(++)$ 程度の neovascularization は 2 例 3 側に認められた. 再出血をきたした症例の neovascularization の程度は Case 5 が $(++)$ であったが, Case 6 は $(+)$ と極めて軽度であった.

\section{考察}

モヤモヤ病成人例では小児例と異なり出血例が多く, 出 血ないし再出血による症状の増悪が問題である(4)1114)18). これら成人例に対する外科的手術の治療効果は以下に示す
ように，小児例ほど，一定していないようである.

馬淵ら ${ }^{5)}$ は, 成人例に対する EMS, encephalo-duroarterio-synangiosis (EDAS), encephalo-myo-arterio-synangiosis (EMAS), superficial temporal-middle cerebral artery anastomosis (STA-MCA) の経験から, 出血例, 虚 血例ともに外科的脳血管吻合術が側副血行路の形成, 脳 底部モヤモヤ血管の縮小の面からみても, 再発予防に有

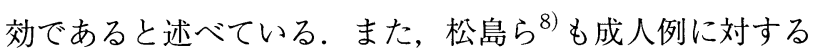
EDAS, encephalo-arterio-synangiosis (EAS)の経験から 馬淵 ${ }^{5)}$ らと同様の見解を示した. このほかにも, 成人例に 対する外科的治療の効果を強調する報告がある ${ }^{10) 12) 15)}$.

一方, 中川ら ${ }^{9)}$ は, 成人の出血例に対して STA-MCA, STA-MCA + EMS, EMS, EMS+EASを行ったものの 約 $20 \%$ に再出血を認めている.

また，最近の鈴木ら ${ }^{16)}$ の学会報告では出血例に対する 

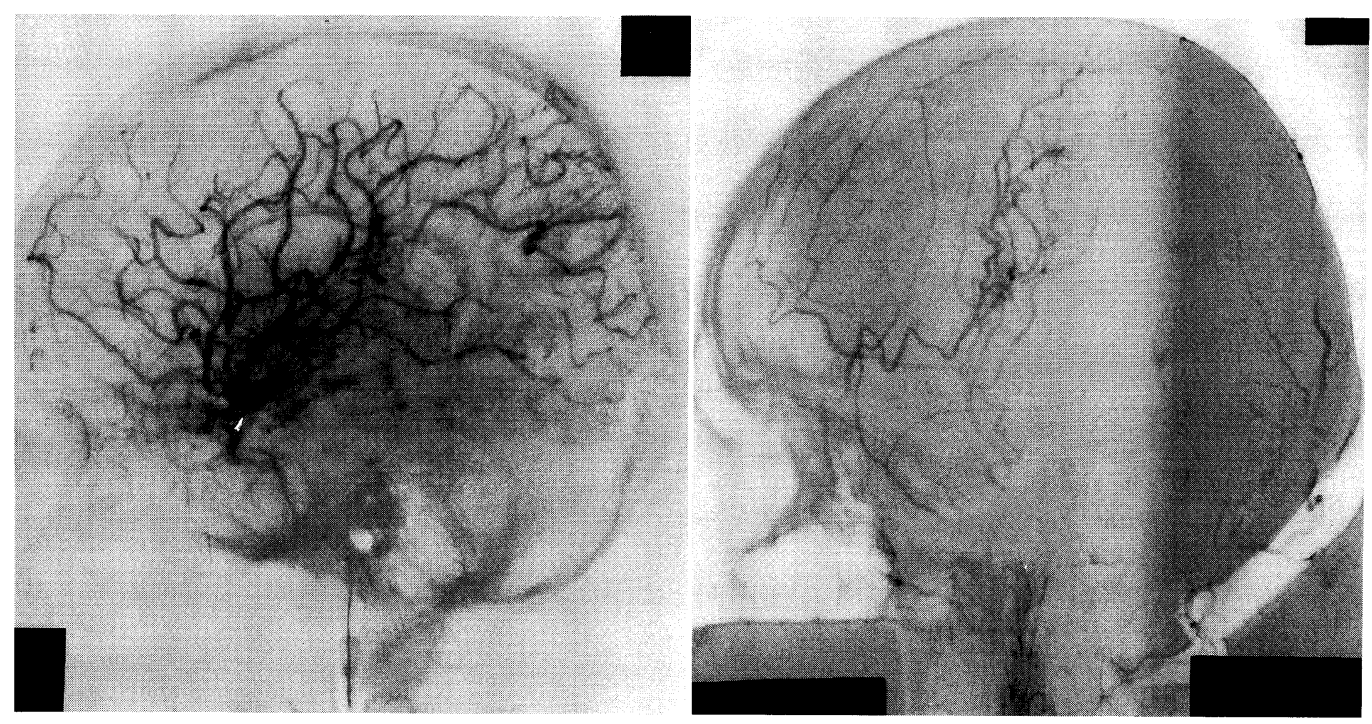

Fig. 5 Left carotid angiograms before (left) and after (right) EMS operation in Case 5 . After the operation, moderate neovascularization $(++)$ was observed in the temporo-fronto-parietal, previously avascular area.
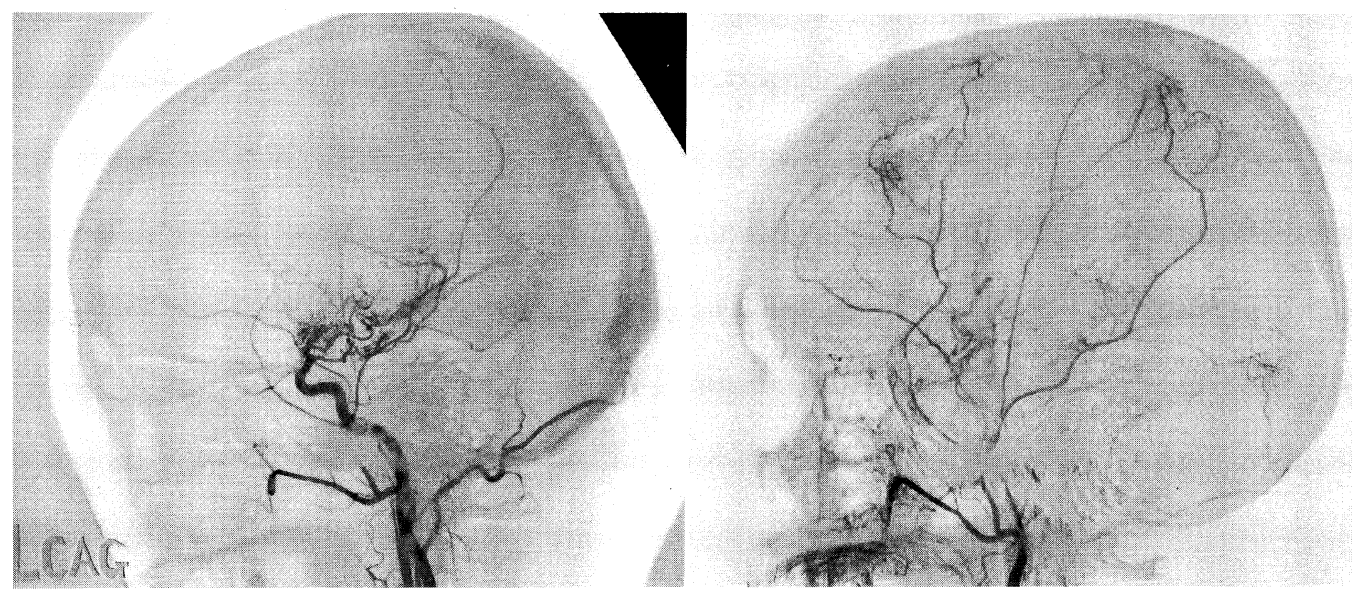

Fig. 6 Left carotid angiograms before (left) and after (right) EMS operation in Case 6. After the operation, mild neovascularization $(+)$ was observed in the temporo-fronto-parietal area.

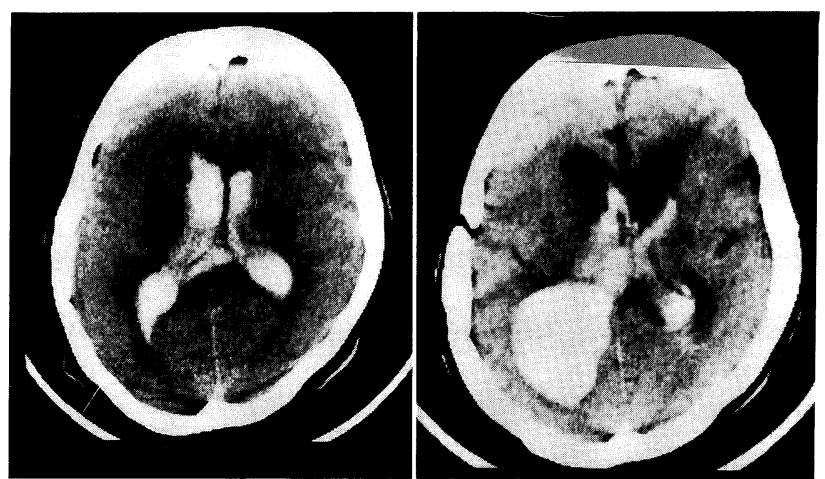

Fig. 7 CT scans before (left) and 24 months after (right) EMS operation in Case 6 showing intracerebral hemorrhage.
脳血管吻合施行例と非施行例では再出血率に差がないと述 べている.

すなわち，経過観察期間が短いなどの問題点もあり，成 人例で外科的手術が再発予防となりうるか否かはいまだに 解明されたとはいえない。

今回の検討では, 我々の経験した虚血例に対する間接的 脳血管吻合術では，十分な neovascularization が認められ た。また，症状の再発も見られず，我々の経験した虚血例 では成人でも間接的脳血管吻合術が侵襲の少ない外科的手 術の first choice として有用であると思われた。

一方, 我々の経験した出血例では虚血例と異なり術後の neovascularizationの程度は少ない傾向を示した。 また， 再出血が 4 例中 2 例に見られ neovascularization の程度と 
再出血の有無との関係も，虚血例ほど明らかではなかった. この結果は成人例における脳血管吻合術の再出血防止効果 に疑問を投げかけた鈴木らの報告 ${ }^{16)}$ を支持するものであ る.

本報告例の出血例における再出血が neovascularization が不十分なためにもたらされるのか？十分な neovascularization を得るために他の脳血管吻合術が必要なのか?

更に, もっと根本的な問題として, 出血例では外科的手 術による neovascularization の形成, 出血防止に限界があ るのか? など不明な点が多い. したがって，外科的手術が 成人例の出血防止になりうるか否かの結論を出すためには 更に症例数を重ね，長期的な観察を必要とする.

\section{結語}

1.モヤモヤ病成人例 6 例に対して間接的脳血管吻合術を 行い，臨床経過および脳血管写所見について検討した。

2. 我々の経験した虚血例では, 十分な neovascularization が得られ，脳血管障害の再発防止の面から見ても 有効であった. しかし, 我々の経験した出血例では満 足すべき結果は得られなかった.

\section{文献}

1) Endo M, Kawano N, Miyasaka $Y$, et al: Cranial burr hole for revascularization in moyamoya disease. J Neurosurg 71: 180-185, 1989

2) Karasawa J, Kikuchi H, Furuse S, et al: A surgical treatment of "moyamoya" disease. "Encephalo-Myosynangiosis". Neurol Med Chir (Tokyo) 17: 29-37, 1977

3) Karasawa J, Kikuchi H, Furuse S, et al: Treatment of moyamoya disease with STA-MCA anastomosis. J Neurosurg 49: 679-688, 1978

4）工藤達之, 福田 栄：ウィリス輪閉塞症. 一疾患単位とし ての病態と病像. 神経進歩 20: 750-757, 1976

5）馬淵正二, 中川 翼, 沢村 豊, ほか：ウイルス動脈輪閉 塞症への血行再建手術後の脳血管撮影所見の検討. 厚生省 特定疾患ウイルス動脈輪閉塞症の成因, 治療, 及び予防に
関する研究班昭和 58 年度研究報告書, 1984, pp 26-31

6) Matsushima Y, Suzuki R, Ohno K, et al: Angiographic revascularization of the brain after encephaloduroarteriosynangiosis: A case report. Neurosurgery 21: 928-934, 1987

7）松島善治，哚井直実，青柳傑，ほか：成人モヤモヤ病に 対する encephalo-duro-arterio-synangiosis (EDAS)の適応 について. 第 10 回脳卒中の外科研究会講演集,にゅーろん 社, 1981, pp 225-229

8）松島善治，鈴木龍太，山口武兼，ほか：成人モヤモヤ病に 対する間接的 $\mathrm{EC} / \mathrm{IC}$ 吻合術の効果. 脳神経外科 14: 15591566, 1986

9）中川 翼, 都留美都雄, 阿部 弘：出血発作を呈したウィ リ又動脈輪閉塞症に対する血行再建手術一手術適応と考え る理論的根拠と自験例の成績一. 厚生省特定疾患ウィリス 動脈輪閉塞症の成因，治療及び予防に関する調查研究班, 昭和 57 年度研究報告書, 1983, pp 115-123

10）中原章徳, 沖 修一, 魚住 徹：Encephalo-Duro-ArterioSynangiosis (EDAS) 施行したモヤモヤ病成人例の 1 治験 例. 広島医学 43: 627-630, 1990

11）西本 詮, 植田清隆, 本間 温, ほか：ウィルス動脈輪閉 塞症の予後調査について．厚生省特定疾患ウィルス動脈輪 閉塞症の成因, 治療及び予防に関する研究班, 昭和 57 年度 班研究会報告書, 1983, pp 66-73

12）龍神幸明，今栄真治，藪本見充雄，ほか：モヤモヤ病の治 療法に関する臨床的検討. 和歌山赤十字病院医誌 6: 46-53, 1988

13）佐伯直勝, 山浦 晶：モヤモヤと脳出血. 臨床成人病 19 : $57-64,1989$

14）佐伯直勝，山浦 晶：モヤモヤ病出血例の検討. 厚生省特 定疾患ウイルス動脈輪閉塞症の成因, 治療及び予防に関す る研究班, 平成元年度班研究会報告書, 1989, pp 143-152

15）柴田尚武：成人モヤモヤ病に扔ける Encephalo-duro-arteriosynangiosis（EDAS）の治療成績. 長崎医学会雑誌 65: 293296, 1991

16）鈴木 諭, 松島俊夫, 藤井清孝, ほか：成人モヤモヤ病の 外科治療一出血型を中心として一。第 21 回日本脳卒中の外 科研究会プログラム抄録集, $1992, \mathrm{p} 284$

17）安川浩司, 奥寺 敬, 本郷一博, ほか：Burr Hole を介して Transcranial Anastomosis を形成した成人モヤモヤ病の 1 例. 脳神経外科 18: 373-378, 1990

18）山口武典, 田代幹雄, 峰松一夫，ほか：ウィリス動脈輪閉 塞症全国調査のまとめ. 厚生省特定疾患ウィルス動脈輪閉 塞症調查研究班, 昭和 54 年度研究報告書, 1980, pp 13-22 